\title{
Fuzzy method of conformity control for compressive strength of concrete on the basis of computational numerical analysis
}

\author{
Izabela Skrzypczak • Lidia Buda-Ożóg • \\ Tomasz Pytlowany
}

Received: 7 January 2015 / Accepted: 12 September 2015/Published online: 14 October 2015

(C) The Author(s) 2015. This article is published with open access at Springerlink.com

\begin{abstract}
All concrete mechanical properties given in design codes of concrete and reinforced concrete structures are correlated with the characteristic compressive strength $\mathrm{f}_{\mathrm{ck}}$. According to the EN 206-1 code, the characteristic strength is defined as the strength value below which $5 \%$ of the population of all possible strength test results for given volume of concrete can be found. The value of $f_{c k}$ can be defined as $5 \%$ quantile of the statistical distribution of the concrete compressive strength, tested on cylindrical samples with a diameter of $150 \mathrm{~mm}$ and a height of $300 \mathrm{~mm}$ or on cubic samples with dimensions $150 \times 150 \times 150 \mathrm{~mm}$ assuming the conversion factor of 0.8 . In order to verify compliance of strength of the considered concrete with the designed characteristic strength (ascribed to concrete class), it should be checked if the test results meet the appropriate statistical criteria. The characteristic strength defined by specifying of concrete class is determined at the designing stage of the structure and it
\end{abstract}

\footnotetext{
I. Skrzypczak $(\bowtie) \cdot$ L. Buda-Ożóg

The Faculty of Civil and Environmental Engineering and Architecture, Rzeszow University of Technology,

Poznańska 2, 35-084 Rzeszow, Poland

e-mail: izas@prz.edu.pl

L. Buda-Ożóg

e-mail: lida@prz.edu.pl

T. Pytlowany

Polytechnic Institute, Krosno State College, Rynek 1,

38-400 Krosno, Poland

e-mail: tompyt@pwsz.krosno.pl
}

is the basic controlled parameter, providing the requirements are fulfilled by the producer. Despite numerous publications on disadvantages of the code compliance criteria, marginalization of the problem is still visible. Concepts and methods based on probabilistic or statistical approaches are often sourced of skeptical views on quality control because they are not very familiar to most engineers. In the paper the assessment of the code compliance criteria has been made using the numerical simulation on the basis of the programs which has been written in $\mathrm{C}++$. The innovative method for estimation test coefficients values contained in the code compliance criteria has been proposed. This method was developed on the basis of fuzzy methods.

Keywords Numerical simulation · Fuzzy method · Compressive strength $\cdot$ Concrete

\section{Introduction}

The class of concrete strength is a value $f_{c k}$ that can be defined as the $5 \%$ quantile of the statistical distribution of concrete compressive strength, tested on cylindrical samples with a diameter of $150 \mathrm{~mm}$ and a height of $300 \mathrm{~mm}$ or on bone samples with dimensions of $150 \times 150 \times 150 \mathrm{~mm}$ with a conversion factor 0.8. According to PN-EN 206-1 [1], characteristic strength is a strength value below which 
$5 \%$ of the population of all possible signs of strength for a given volume of concrete can be found. In order to verify the compliance of the strength of the considered part of concrete with the designed characteristic strength (assigned to the class of concrete), it needs to be checked whether the results of sample tests meet the required statistic criteria. Characteristic strength determined by specifying the concrete class is established at the design stage of construction and is the basic controlled value, proving that the manufacturer's requirements are fulfilled. In the norms of design of concrete and reinforced structures all mechanical properties of concrete are correlated with the characteristic compressive strength $f_{c k}$. In the Eurocode 2 [2] norm there is a table where different characteristics required for a design are assigned to particular concrete class. Thus, usually only value $f_{c k}$ applied in the project is based on sample research, other features of concrete are tested empirically only in special cases. It should be emphasized that the most commonly used test methods described in the norm [1] aim in checking compliance of the strength with the specifications, and not in determining characteristic strength of concrete.

Uncertainties associated with the assessment and classification of concrete strength are fuzzy and nonrandom. A typical situation when the fuzzy uncertainty needs to be taken into account is the assessment of compatibility of concrete strength and the determination of the effect of concrete class on the steelconcrete composition. Therefore, the aim of this study is to propose a numerical analysis of the behavior of reinforcing steel depending on the concrete class and to propose an analytical procedure for statistical and fuzzy classification of concrete, which takes into consideration marginal distribution of adjacent classes and limits the number of considered levels of concrete compressive strength.

\section{Concrete-reinforcement bond versus defined concrete class}

One of experimental studies and analysis recently taken into account in the literature is the impact of the concrete-reinforcement bond [3]. In order to clarify the effect of the concrete class on the concretereinforcement bond the authors carried out numerical calculations. Based on the results, an analysis of the impact of the selection of the concrete class on the distribution of stresses in concrete against cracking was performed, with a particular emphasis on the stress distribution of adhesion. The analysis were limited to consideration of the impact of mechanical properties of concrete in the area of concrete-reinforcement bond.

The main factor of concrete-reinforcement bond is adhesion. Adhesion mechanism is mainly influenced by: (a) chemical bond between both materials, (b) adhesion, (c) mutual engagement of the two materials [4]. In addition, the shrinkage has a positive effect on the adhesion because it produces a concentric pressure of the bar in concrete. Figure 1 shows a graph of stress distribution of adhesion between concrete and steel $\tau_{p}$ $(x)$ and of stress in the removable bar $\sigma_{s}(x)$ with a diameter $d$.

A function describing stress distribution of the adhesion is not yet known exactly. Also there are no clearly defined limits of adhesion stress $\tau_{p, \max }=f_{p}$. Thus, a mean value of adhesion stress is often used $\bar{\tau}_{p}$ [5].

A complete destruction of adhesion has a stepwise character and its mechanism depends on many factors. After an increasing tensile force is applied to the smooth rebar embedded in concrete under a certain load, there is a adhesion rupture associated with

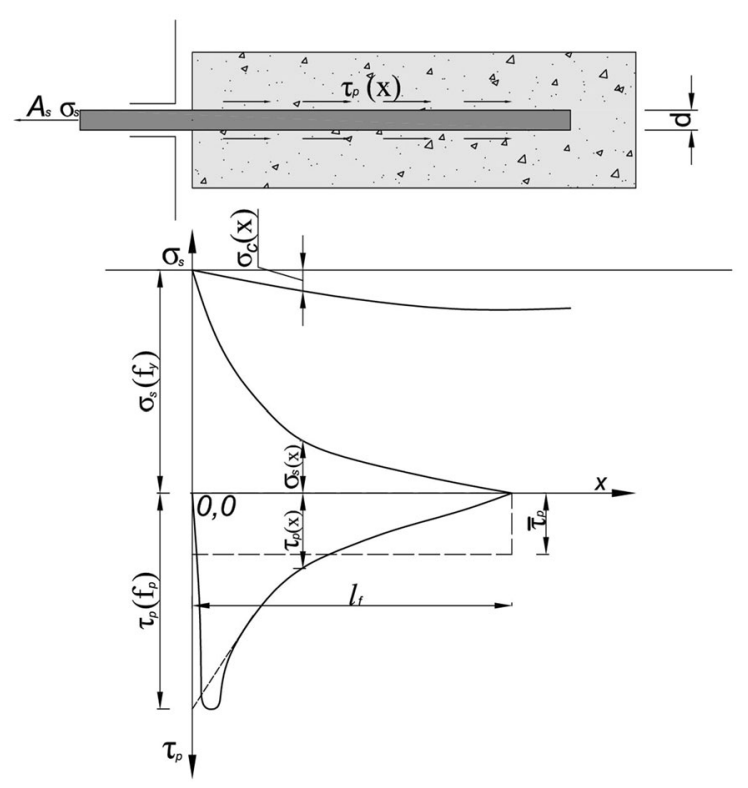

Fig. 1 Stress distribution of adhesion between concrete and steel $\tau_{p}(x)$ and of stress in the removable $\operatorname{bar} \sigma_{s}(x)$ [5] 
chemical adhesion and friction. As a result of a crack, a certain continuity of deformation of the two materials (i.e. the initial adhesion) is interrupted and a relative slip occurs. Further increase of the load promotes the formation of another cracks radiating from the bar and propagating through the cover of concrete, until the cover bursts.

\section{Numerical calculations}

The numerical calculations used one type of reinforced concrete elements, differing with defined concrete class C16/20, C20/C25 25/30. The elements were analyzed using 3 bars of $12 \mathrm{~mm}$ diameter. Dimensions of the element are as follows: width $150 \mathrm{~mm}$, height $300 \mathrm{~mm}$. The distances between the bars are $44 \mathrm{~mm}$, the lagging is of $24 \mathrm{~mm}$. Figure 2 shows the static diagrams for the analyzed element and the adopted finite element mesh. Calculations were performed using the ADINA program including the nonlinear characteristics of the materials. It was assumed that the stress analysis in the elements in the pure share stress state will be performed in a plane state of stress. In the case of reinforcing steel reaching the boundary condition was checked by the Mises Huber hypothesis and in the case of concrete, the analysis was based on the Drucker-Prager hypothesis [4]. Concrete tensile strength, the average concrete compressive strength or modulus of elasticity of concrete were determined based on empirical formulas. Tensile strength of concrete $f_{c t, e f f}$, can be determined based on the value of compressive strength $f_{c k}$ according to the formula (1):

$f_{c t, e f f}=0,3 \cdot f_{c k}^{2 / 3}$

The average compressive strength of concrete: $f_{c m}=f_{c k}+8$

$E_{S}$ and $E_{c m}$ are modules (mean values) of elasticity of reinforcing steel and concrete. $E_{c m}$ is often defined according to the characteristic compressive strength of concrete $f_{c k}$ according to the formula (3)

$E_{c m}=\frac{9500}{1,1}\left(f_{c k}+8\right)$

3.1 The calculation model

ADINA program was used as a tool for numerical analysis. This program gives the opportunity to perform calculations using finite element method. Spatial elements, for which certain material data and boundary conditions had been assigned, were used to perform numerical model. Two material models were used for the junction analysis: elastic-plastic model and plastic model in order to reinforce steel rods and concrete. Characteristics of the materials were chosen the way that modulus of elasticity, tensile strength, compressive strength, yield strength, etc., were compatible with existing materials in use. Different mechanical properties of the analyzed material are presented in Sect. 3 of this work. The combination of spatial elements made of various materials were modeled as a total junction. Model load was achieved by applying forced displacements to the elements simulating reinforcement bars. The model was analyzed several times, changing the characteristics of the material model for each class of concrete mentioned in Sect. 3 of this work. The results of the analysis are shown in Fig. 2. The charts and readings of stresses and displacements show clear evidence of the impact of the material used on the results. When strength increases, force required for the creation of scratches in concrete (Fig. 2) to achieve destruction of the
Fig. 2 Adhesion stress distribution between concrete and steel and distribution of stresses in the pulled off bar a Mode1 b Model 2 c Model 3 (a)

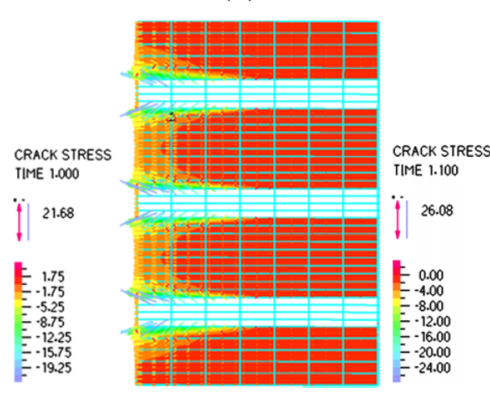

(b)

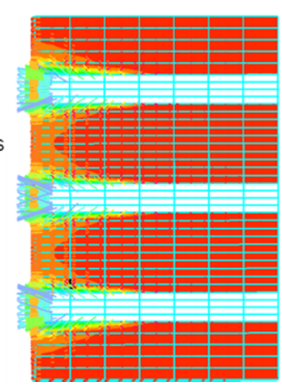

(c)

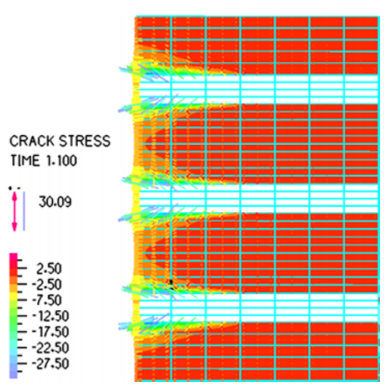


material by tearing it apart, increases noticeably as well.

Finally, numerical analysis parameters were adopted for particular classes of concrete in accordance with Table 1 . The steel of the type A with characteristic elasticity range $\mathrm{f}_{\mathrm{yk}} 500 \mathrm{MPa}$.

\subsection{Theoretical analysis performed on three different models}

The tangential stress alters the stress of a bar embedded in concrete, and adhesion stress is the greater, the faster the increase in the pulling off force applied to the bar. Determination of a pull-off strength of reinforced concrete bar shown in Fig. 2 for different classes of concrete and a dislocation of its unloaded end enabled to determine the adhesion tension in the studied models. These stresses were found to be greater than the minimum stress provided in the standard PN EN 10080: 2005. In the analysis, the anchorage length was only $5 \mathrm{~d}$, just like in laboratory models; these samples are analyzed by a pull-off method [6]. The caused adhesion tension for a given series of tests are shown in the Table 2 below.

Theoretical analysis performed on three different models according to the defined class of concrete has confirmed that the mechanical properties of concrete have a significant impact on the value of adhesion stress. It is believed that the adhesion determines stress distribution in steel and concrete along the bar after being scratched. However, a clear identification of concrete classification is problematic. It has a fuzzy nature. Therefore, the further part of the article is devoted to the proper classification of concrete.

\section{Fuzzy criteria of compliance of concrete strength}

The results of the analysis of numerical simulation were the basis for carrying out fuzzy classification of concrete. The results of verification of compliance of concrete compressive strength can be considered as a random event and conformity criteria for values with fuzzy borders. Measures of compliance, on the basis of which the quality of the concrete is assessed, is likely to have a probability character of which a random event will be in the area with fuzzy borders (by Zadeh), or the fuzzy number (with a known membership function corresponding to the probability that the event will be up to a certain range (by Yager) [7].Concrete compressive strength $f_{c}$ meeting double compliance criteria can be written with a fuzzy set (4):

$f_{c}=\left[\mu_{f, C}\left(f_{c m}\right), f_{c}\right], \quad \mu_{f, C}: F_{c} \rightarrow[0,1]$

Where: $\mu_{f, C}\left(f_{c m}\right)$ is a membership function assigning to each element of the set of strength $f_{c} \in F_{c}$ the membership level to the fuzzy set $f_{c}$ from the interval $[0,1]$.

The decision on the inclusion of a concrete batch to the designed concrete class depends, as a rule, on the

Table 1 The material parameters for each of the analyzed models

\begin{tabular}{lllllll}
\hline Model & $\begin{array}{l}\text { Concrete } \\
\text { class }\end{array}$ & $\begin{array}{l}\text { The average compressive } \\
\text { strength of concrete } \mathrm{f}_{\mathrm{cm}} \\
{[\mathrm{MPa}]}\end{array}$ & $\begin{array}{l}\text { Deformation of } \\
\text { concrete in } \\
\text { compression }\end{array}$ & $\begin{array}{l}\text { Tensile strength of } \\
\text { concrete } \mathrm{f}_{\mathrm{ct}, \mathrm{eff}} \\
{[\mathrm{MPa}]}\end{array}$ & $\begin{array}{l}\text { Characteristic } \\
\text { strength of } \\
\text { concrete } \mathrm{f}_{\mathrm{ck}}\end{array}$ & $\begin{array}{l}\text { Modulus of } \\
\text { elasticity of } \\
\text { concrete } \mathrm{E}_{\mathrm{cm}}[\mathrm{GPa}]\end{array}$ \\
\hline 1 & $\mathrm{C} 16 / 20$ & -24 & -0.0035 & 1.90 & 16 & 29 \\
2 & $\mathrm{C} 20 / 25$ & -28 & -0.0035 & 2.20 & 20 & 30 \\
3 & $\mathrm{C} 25 / 30$ & -33 & -0.0035 & 2.60 & 25 & 31 \\
\hline
\end{tabular}

Table 2 Caused adhesion tension for given dislocations

\begin{tabular}{llll}
\hline Dislocation & \multicolumn{2}{l}{ Caused adhesion tension for given dislocations $\tau / f_{c m}$} \\
\cline { 2 - 4 }$\Delta[\mathrm{mm}]$ & Model 1 & Model 2 & Model 3 \\
\hline 0.01 & 0.44 & 0.49 & 0.52 \\
0.1 & 0.63 & 0.73 & 0.77 \\
1 & 0.88 & 0.92 & 0.98 \\
$\tau_{b m} / f_{c m}$ & 0.65 & 0.71 & 0.76 \\
\hline
\end{tabular}


fulfillment of a condition imposed on the average strength from a sample $f_{c m}$. Occasionally, a decisive condition is to reduce the minimum strength of the sample $f_{c i}[8-11]$.

\subsection{Statistical-fuzzy classification of concrete}

Double by standards compliance criteria of a produced concrete batch with the designed class can be written as (5) and (6):

- for a sample $n=3$ :

$$
\left.\begin{array}{c}
f_{c m} \geq f_{c k}+4 \\
f_{c i} \geq f_{c k}-4
\end{array}\right\}=K
$$

- for a sample $n=15$ :

$$
\left.\begin{array}{l}
f_{c m} \geq f_{c k}+1,48 \sigma \\
f_{c i} \geq f_{c k}-4
\end{array}\right\}=K
$$

Test characteristics $K$ is the fuzzy value with the membership function $\mu_{f c}\left(f_{c m}\right)$, which can be determined for certain classes of concrete based on statistical and fuzzy experiment.

\subsubsection{Approximation of membership function}

In order to determine the membership function for the above classes of concrete (three neighboring segments) the fuzzy-statistical (three-phase) method was used [12]. The presented analysis is an extension of the propositions of Wolinski [13].

The first stage of a statistical fuzzy methods is to determine the parameters of the boundary distributions, therefore random variables $\xi$ and $\eta$ were defined. The variable $\xi$ represents a point of value distribution of test characteristics $K$ for a considered and lower class of concrete, and $\eta$ represents a point of distribution of a considered and lower class of concrete. It was assumed that the pair $(\xi, \eta)$ is a two-dimensional normal random variable for which the marginal distributions $p_{\xi}(k)$ and $p_{\eta}(k)$ of random variables $\xi \rightarrow N\left(m_{\xi}, \sigma_{\xi}\right)$ i $\eta \rightarrow N\left(m_{\eta}, \sigma_{\eta}\right)$ can be determined.

Membership function of test characteristics $K_{i}$ for a considered $i$ class of concrete and lower can be described by the following formula (7):
$\mu_{C i}\left(f_{c m}\right)=\int_{-\infty}^{f_{c m}} p_{\eta}\left(f_{c m}\right) d f_{c m}=F\left(\frac{f_{c m}-m_{\eta}}{\sigma_{\eta}}\right)$

Membership function of test characteristics Ki for a considered $i$ class of concrete and higher can be described by the following formula (8):

$\mu_{C i-1}\left(f_{c m}\right)=\int_{f_{c m}}^{+\infty} p_{\xi}\left(f_{c m}\right) d f_{c m}=1-F\left(\frac{f_{c m}-m_{\xi}}{\sigma_{\xi}}\right)$

In contrast, a fuzzy membership function of the considered $i$ concrete class $f_{c i}$, can be calculated from the formulas (9) and (10):

$\mu_{C i+1}\left(f_{c m}\right)=1-\int_{f_{c m}}^{+\infty} p_{\xi}\left(f_{c m}\right) d f_{c m}-\int_{-\infty}^{f_{c m}} p_{\eta} f\left(f_{c m}\right)$

$\mu_{C i+1}\left(f_{c m}\right)=1-\left[1-F\left(\frac{f_{c m}-m_{\xi}}{\sigma_{\xi}}\right)\right]-F\left(\frac{f_{c m}-m_{\eta}}{\sigma_{\eta}}\right)$

Finally, the formula takes the following form (11):

$\mu_{C i+1}\left(f_{c m}\right)=F\left(\frac{f_{c m}-m_{\xi}}{\sigma_{\xi}}\right)-F\left(\frac{f_{c m}-m_{\eta}}{\sigma_{\eta}}\right)$

Where:

$F(z)=\frac{1}{\sqrt{2 \pi}} \int_{-\infty}^{z} \exp \left(-0,5 z^{2}\right) d z$

With a membership function of test characteristics for different classes of concrete and the average strength of adjacent classes, estimated on the basis of a random simulation, a degree of membership of the considered concrete batch to different classes can be specified. Depending on the value $\mu_{K}\left(f_{c m}\right)$ a decision on including a given concrete batch to the appropriate class of concrete can be taken. This decision may be more or less careful, depending on the quality of the produced concrete and its impact on ensuring the safety of the ongoing construction. 


\subsubsection{Example of the application of statistical-fuzzy compatibility criteria}

For the considered compliance criteria for consideration in the form of calculations were performed by generating 100,000 groups of a random numbers of a size $n=3$ compatible with normal distribution, by drawing concrete class (concrete of three neighboring segments $\mathrm{Ci}-1, \mathrm{Ci}, \mathrm{Ci}+1$-the same probability of selection 1/3), standard deviation, and defectiveness. To generate random numbers with standard normal distribution a Box and Muller polar method [14] was used. A function table of the probability distribution of the random vector $(\xi, \eta)$ was built and the histogram of boundary distributions was set, summing up the rows and columns: the first one (the sum of lines) - by classifying according to the considered and a lower class of concrete, the second one (the sum of columns) by classifying according to the considered and higher grade concrete. Function charts of marginal density distributions of probability $\mathrm{p}_{\xi}\left(\mathrm{x}_{\mathrm{n}}\right)$ and $\mathrm{p}_{\eta}\left(\mathrm{x}_{\mathrm{n}}\right)$ were the basis for the designation of membership function of test characteristics for each class of concrete [14].

On the basis of simulation for the concrete class $\mathrm{C} 16 / 20$, by generating 100,000 groups of random numbers of size $n=3$ compatible with a normal distribution density functions of marginal distributions and fuzzy membership functions of test characteristics of each class of concrete (three adjacent concrete classes) were estimated.

Considerations were performed for a concrete class $\mathrm{C} 16 / 20$, with the following parameter estimates of marginal distribution of the random variable $\xi \rightarrow \mathrm{N}$ $\left(\mathrm{m}_{\xi}, \sigma_{\xi}\right)$, i.e. a chapter point for concrete class $\mathrm{C} 12 / 15$ and $\mathrm{C} 16 / 20, \mathrm{~m}_{\xi}=10,19 \mathrm{MPa}$, and $\sigma_{\xi}=3,29 \mathrm{MPa}$. Parameters of the marginal distribution of the random variable $\eta \rightarrow \mathrm{N}\left(\mathrm{m}_{\eta}, \sigma_{\eta}\right)$, chapter point for the concrete class $\mathrm{C} 16 / 02$ and $\mathrm{C} 20 / 25$ was estimated to be $\mathrm{m}_{\eta}=21,72 \mathrm{MPa}$ i $\sigma_{\eta}=2,18 \mathrm{MPa}$.

Density functions intersect at various points which implies large number of classes presented in the standard, hindering clear understanding of its classification. Figure 4 presents other classes of concrete for a broader classification.

Based on the determined membership function (Fig. 3), it can be concluded that the batches of concrete for which the average strength from the sample is $15,8 \mathrm{MPa}$ can be, with a degree of certainty of 0.82 classified as a class of $\mathrm{C} 16 / 20$. When the

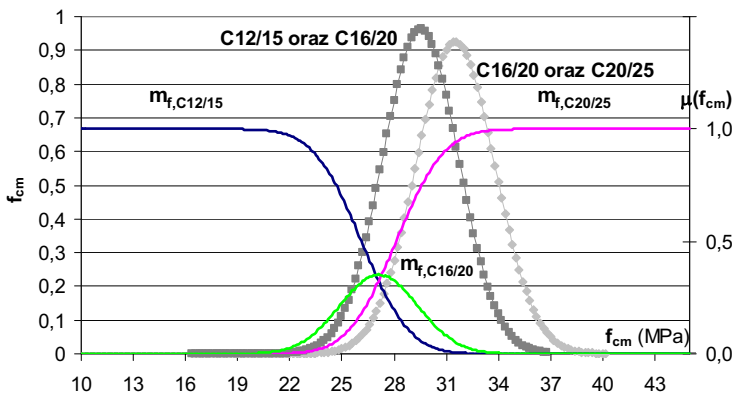

Fig. 3 Membership functions for each class and density functions of marginal distributions for the considered class of concrete $\mathrm{C} 16 / 20$ and the adjacent classes

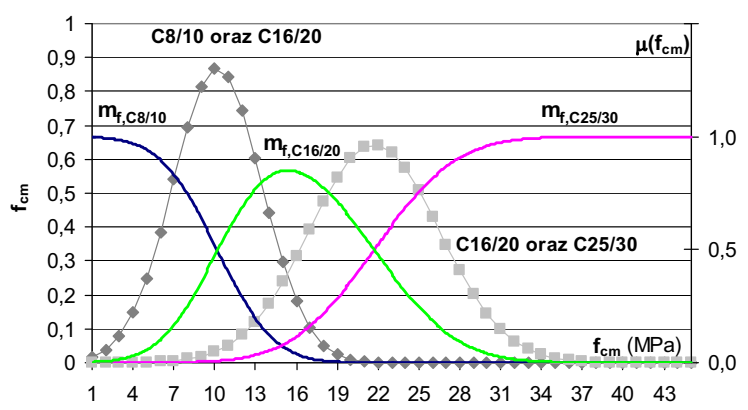

Fig. 4 Membership functions for each class and density functions of marginal distributions for the considered class of concrete $\mathrm{C} 16 / 20$ and every other class

batches of concrete have an average compressive strength range $(10 ; 15.8) \mathrm{Mpa}$, the produced concrete, with a degree of confidence from 0.5 to 0.82 , can be classified to $C 16 / 20$ or $C 8 / 10$. When the value of the coefficient belongs to the range of 15.8 to $22.0 \mathrm{Mpa}$, it can be classified to $\mathrm{C} 25 / 30$ with a degree of certainty from 0.08 to 0.5 .

\section{Conclusions}

The use of statistical-fuzzy method for a classification of concrete showed that the proposed standardized classification of concrete contains too many concrete classes with distributions often overlapping. This means that the criteria used by standards are "insensitive" and may lead to an underestimation or overestimation of a concrete class. The use of concrete significantly stronger than designed is not appropriate, because it can cause a wide cracking. Required 
minimum reinforcement depends on the class of concrete and the greater the reinforcement the stronger the concrete.

Mechanical properties of concrete are strongly dependent on the composition, that is why correlated values based on the norm table recommended in Eudocod 2 [2], clearly assigned to strength classes should be considered only as indicative guidelines that are appropriate in common use. In special cases, various mechanical properties of the concrete should be determined experimentally.

Open Access This article is distributed under the terms of the Creative Commons Attribution 4.0 International License (http:// creativecommons.org/licenses/by/4.0/), which permits unrestricted use, distribution, and reproduction in any medium, provided you give appropriate credit to the original author(s) and the source, provide a link to the Creative Commons license, and indicate if changes were made.

\section{References}

1. PN-EN 206-1 (2014) Concrete-Part 1: specification, performance, production and conformity

2. Eurocode 1992-1-1 (2004) Eurocode 2: Design of concrete structures, Part 1-1: General rules and rules for buildings

3. Arel HŞ, Yazıcı Ş (2012) Concrete-reinforcement bond in different concrete classes. Constr Build Mater 36:78-83
4. Smarzewski P, Stolarski A (2007) Tests and stress determination of a bond between concrete and reinforcing steel. Bull WAT 56(1):7-24

5. Słowik M, Błazik Borowa E (2001) The influence of the choice of reiforcement's bars on stress distribution in concrete element. Maint Reliab 5:33-46

6. Gambarova PG, Rosati GP (1996) Bond and splitting in reinforced concrete: test results on bar pull-out. Mater Struct RILEM 29:267-276

7. Yager R, Filev D (1995) Essentials of fuzzy modeling and control. WN-T, Warsaw

8. Caltarino JMR (1998) Statistical criteria for acceptance of materials performance of concrete standards ENV 206:1993 and prEN 206; 12 th ERMCO Congress. In: Proceedings, Vol. 1, Lisbon

9. Taerwe L (1988) Evaluation of compound compliance criteria for concrete strength. RILEM Mater Struct 21:13-20

10. Holicky M, Vorlicek M (1992) Fractile estimation and sampling inspection in building. Acta Polytechnica, CVUT Praha 32(1):87-96

11. Skrzypczak I, Woliński SZ (2007) Influence of distribution type on the probability of acceptance of conformity criteria for concrete strength. Arch Civ Eng 53(3):479-495

12. Li H, Yen VC (1995) Fuzzy sets and fuzzy decision-making. CRC Press, Boca Raton

13. Woliński SZ (1999) Statistical and fuzzy compatibility criteria of compressive strength of concreto, vol 247. Cracow University of Technology, Monografie, Cracow

14. Brandt S (1998) Data analysis. Wydawnictwo Naukowe PWN, Warsaw 